\title{
Langerhans cell histiocytosis: a 16-year experience
}

\author{
Márcia Kanadani Campos, ${ }^{1}$ Marcos Borato Viana, ${ }^{2}$ Benigna Maria de Oliveira, ${ }^{3}$ \\ Daniel Dias Ribeiro, ${ }^{4}$ Cláudia Márcia de Resende Silva ${ }^{5}$
}

\begin{abstract}
Objectives: To describe the clinical course of Langerhans cell histiocytosis and to compare its outcome according to age, staging of the disease and treatment response.

Methods: Retrospective analysis of data on 33 children with Langerhans cell histiocytosis followed at Hospital das Clínicas, Universidade Federal de Minas Gerais, Brazil, between 1988 and 2004.

Results: Age at diagnosis ranged from 2 months to 16 years (median: 2.5 years). Seventeen children were male. The follow-up period varied from 21 days to 16.2 years (median: 3.4 years). The most common clinical manifestations at diagnosis were osteolytic lesions, enlarged lymph nodes and skin lesions. The overall survival rate for the whole group was $86.1 \%$ at 16 years (95\%CI 66.6-94.6\%). Deaths occurred in patients with multisystem disease and organ dysfunction at diagnosis. Those patients who had a "better" response to treatment in the sixth week were likely to have a significantly higher overall survival rate than those who showed disease progression. Overall survival rate was significantly higher for patients with single-system disease. The disease-free survival rate for the whole group was $30.9 \%$ at 16 years (95\% CI $15.6-47.5 \%)$, and was significantly higher for those with single-system disease. Age groups were not associated with different disease-free survival rates. Diabetes insipidus was the most common sequela. No cases of secondary neoplasms were observed.
\end{abstract}

Conclusion: The clinical manifestations of Langerhans cell histiocytosis vary widely, with a high relapse rate and low mortality rate.

J Pediatr (Rio J). 2007;83(1):79-86: Langerhans cell histiocytosis, diagnosis, therapy, complications.

\section{Introduction}

Langerhans cell histiocytosis ( $\mathrm{LCH}$ ) is a rare and scarcely known disease. In 1987, after the launching of the International Histiocyte Society, histiocytoses were

1. Mestre. Serviço de Hematologia, Hospital das Clínicas, Universidade Federal de Minas Gerais (UFMG), Belo Horizonte, MG, Brasil.

2. Doutor. Professor titular, Departamento de Pediatria, Faculdade de Medicina, UFMG, Belo Horizonte, MG, Brasil.

3. Doutora. Professora adjunta, Departamento de Pediatria, Faculdade de Medicina, UFMG, Belo Horizonte, MG, Brasil.

4. Médico hematologista, Serviço de Hematologia, Hospital das Clínicas, UFMG, Belo Horizonte, MG, Brasil.

5. Mestre. Serviço de Dermatologia, Hospital das Clínicas, UFMG, Belo Horizonte, MG, Brasil.

Manuscript received Jun 07 2006, accepted for publication Aug 302006.

Suggested citation: Campos MK, Viana MB, de Oliveira BM, Ribeiro DD, Silva CM. Langerhans cell histiocytosis: a 16-year experience. J Pediatr (Rio J). 2007;83(1):79-86.

doi 10.2223/JPED. 1581 reclassified into three major classes. ${ }^{1}$ Class I was called Langerhans cell histiocytosis, replacing the different nomenclatures that had been historically in use: histiocytosis $X$, eosinophilic granuloma, Hand-SchüllerChristian disease, Letterer-Siwe disease, HashimotoPritzker disease, among others. These nomenclatures showed the wide variety of clinical manifestations that characterized the disease, eponyms, or lack of knowledge about its etiopathogenesis. Class II includes nonLangerhans cell histiocytosis. Class III encompasses malignant histiocyte disorders. In 1997, the World Health Organization broadened the classification, but kept the term $\mathrm{LCH}^{2}{ }^{2}$

LCH results from the clonal proliferation of Langerhans cells, and its etiopathogenesis is still unknown. ${ }^{2}$ The hypothesis that it is a neoplastic or inflammatory disease, as well as the existence or not of immunological, viral or 
genetic predisposing factors, has been widely discussed in the literature, but no conclusive proof has ever been provided. ${ }^{3-5}$

LCH can be diagnosed in any age group, but it affects mainly children. ${ }^{6-9}$ Its estimated annual incidence among children ranges from three to four cases per million. However, this incidence may be underestimated, due to the resemblance of localized forms to other pathologies and due to the possibility of spontaneous remission. ${ }^{10,11}$

Both the clinical presentation and outcome of LCH vary widely. Virtually all tissues can be affected by the disease, which may be characterized by solitary lesions in a single organ or by disseminated disease with organ dysfunction. The most commonly affected sites are the bones, skin, and lymph nodes. The disease may resolve spontaneously or progress and compromise the function of vital organs, with severe and fatal consequences. ${ }^{10}$

The lack of knowledge about the etiopathogenesis of the disease hinders the development of a rational therapeutic approach. Nevertheless, the comparison between the results of international cooperative studies indicates that chemotherapy can have a positive influence on the natural course of the disease by reducing the number of relapses and sequelae in cases of multisystem disease, multifocal bone disease and localized disease at special sites (facial bones and bones of the middle cranial fossa and intraspinal lesions). ${ }^{12}$ In cases of single-system disease - except for multifocal bone disease and localized disease at special sites -, treatment depends on each and every situation.

The possibility of relapses and sequelae causes remarkable morbidity in all patient groups. There is a paucity of data about the actual incidence of sequelae, and the unpredictability of the clinical course is quite distressing, being a burden to the children and their families. ${ }^{13}$

Since $\mathrm{LCH}$ is a rare disease and we lack data about its clinical course in Brazil, the aim of the present study is to describe the clinical course and outcome of this disease in a group of children and adolescents diagnosed and treated in a single institution.

\section{Methods}

A retrospective and descriptive study was carried out using the data obtained from medical charts and from the results of histopathologic and immunohistochemical exams of children and adolescents with $\mathrm{LCH}$, diagnosed and treated at the Division of Hematology of Hospital das Clínicas (HC) of Universidade Federal de Minas Gerais (UFMG), Brazil, between 1988 and 2004.
The diagnostic criteria were based on the International Histiocyte Society recommendations. ${ }^{1}$ The presumptive diagnosis was established based on conventional histological findings. The presence of these findings, coupled with immunohistochemical results showing positive S-100 protein staining, was regarded as probable diagnosis. The definitive diagnosis was made using electron microscopy, with the detection of Birbeck granules, or positive CD1a antigen expression by way of immunohistochemistry.

For staging purposes, all of the patients were submitted to clinical assessment, laboratory tests and radiological examination - X-rays of the skull, hip, chest and long bones, according to the protocol of the institution. The fluid deprivation test was performed and immunoglobulin concentration was measured when, respectively, diabetes insipidus or immunodeficiency was clinically suspected. A myelogram was performed if the patient showed thrombocytopenia, leukopenia or anemia of unknown etiology.

The children were retrospectively classified into the following stages:

- Stage I: Single-system disease.

- Single site: solitary bone lesion, isolated skin involvement or involvement of a single lymph node;

- Multiple sites: several bone lesions; involvement of more than one lymph node.

- Stage II: Multisystem disease with involvement of more than one organ, with or without dysfunction. The following criteria were used to assess organ dysfunctions: ${ }^{8}$

- Liver dysfunction: hypoalbuminemia and/or prothrombin activity less than $50 \%$ and/or signs of cholestasis or a fivefold increase in liver enzymes;

- Hematopoietic system: hemoglobin level less than 10 $\mathrm{g} / \mathrm{dL}$ and/or platelet count less than $100 \times 10^{9} / \mathrm{L}$ and/or total leukocyte count less than $4 \times 10^{9} / \mathrm{L}$ and/or neutrophil count less than $1.5 \times 10^{9} / \mathrm{L}$; other causes were ruled out;

- Pulmonary dysfunction: signs of dyspnea or cyanosis; alveolar or interstitial infiltrate on chest X-ray, in the absence of infection.

As this was a retrospective study, no criteria were previously established for clinical remission. The healing of lytic lesions, reduction in the size of lymph nodes, resolution of visceromegaly, absence of fever, healing of skin lesions, and normalization of laboratory parameters were regarded as signs of therapeutic response. The patients were categorized into three groups according to their responses: ${ }^{14}$ 
- "Better" response: total resolution or continuous remission of the disease;

- Intermediate response: stable disease and patients with remission of the disease at some sites, with development of lesions at other sites;

- Lack of response: disease progression.

The regimens used as initial treatment are described in Table 1.

Relapse of the disease was defined as the development of new lesions or organ dysfunction after a 3-month stable course; any irreversible clinical condition occurring at any time during the course of the disease was regarded as a sequela.

The Kaplan-Meier method was used to estimate the probability of overall survival (OS) and of disease-free survival (DFS). Death and relapse of the disease were used to estimate the DFS, and those patients who did not suffer any event were censored at the last follow-up date. The log-rank test was used to compare the survival curves. A p value $\leq 0.05$ was established as statistically significant. $A$ multivariate analysis was not performed due to the small number of patients. The age of 3 years was used as cutoff point for age stratification. The study protocol was approved by the Research Ethics Committee of UFMG.

\section{Results}

During the study period, 33 patients (17 males) with LCH were diagnosed and treated at HC-UFMG. Age at diagnosis ranged from 2 months to 16 years, with a median of 2.5 years. The follow-up period ranged from 21 days to 16.2 years, with a median of 3.4 years.

Definitive diagnosis was made in seven children, and was based on CD1a antigen expression in four cases and on electron microscopy in three cases.

The most common clinical manifestations at diagnosis (Table 2) were ostelolytic lesions, found in 23 patients $(69.7 \%)$. The skull was the most commonly affected site (78.3\% of cases). Enlarged lymph nodes were present in 16 children at diagnosis (48.5\%). Of these, 14 showed enlarged cervical lymph nodes $(87.5 \%)$, which were affected more frequently. Skin or mucocutaneous lesions were described in 11 patients (33.3\%), and had been previously diagnosed as psoriasis in one patient, seborrheic dermatitis in five and allergy in one. Six children showed ear involvement in the initial assessment. Otorrhea was present in two children, recurrent otitis media in one child, and auditory canal mass in two. One child who complained of otorrhea had normal otoscopic findings and no skull lesions, but symptoms improved after treatment.

Patient distribution according to initial treatment is shown in Table 1. Three patients with diabetes insipidus were treated with radiation given to the hypothalamic

Table 1 - Distribution of 33 patients with Langerhans cell histiocytosis, according to initial treatment

\begin{tabular}{lc}
\hline Initial treatment & No. of patients \\
\hline Not treated & $2(6 \%)$ \\
$\begin{array}{l}\text { Prednisone only } \\
\left(40 \mathrm{mg} / \mathrm{m}^{2} / \text { day for } 6 \text { weeks) }\right.\end{array}$ & $3(9.1 \%)$ \\
$\begin{array}{l}\text { Vinblastine }\left(6.5 \mathrm{mg} / \mathrm{m}^{2} / \text { week for } 12 \text { weeks) }\right. \\
+ \text { Prednisone }\left(40 \mathrm{mg} / \mathrm{m}^{2} / \text { day for } 6 \text { weeks }\right)\end{array}$ & $16(48.5 \%)$ \\
$\begin{array}{l}\text { Etoposide }\left(150 \mathrm{mg} / \mathrm{m}^{2} / \text { day for } 3 \text { days: } 3 \text { to } 6 \text { cycles }\right. \\
\text { with an interval of } 3 \text { to } 4 \text { weeks between the cycles) }\end{array}$ & $6(18.2 \%)$ \\
$\begin{array}{l}\text { Surgical excision } \\
\text { Other }+\end{array}$ & $3(9.1 \%)$ \\
\hline
\end{tabular}

* One patient with diabetes insipidus at diagnosis was treated with radiation given to the hypothalamic region, immediately after diagnosis, with the concomitant use of etoposide. ${ }^{15}$

† Others: one patient with vulvar lesions received an intralesional injection of corticosteroid in another institution; one patient received two cycles of vinblastine and prednisone, which were discontinued due to septic shock, and no other additional treatment was necessary due to remission of the disease; one patient initially received three doses of etoposide. 
region (total dose, $900 \mathrm{cGy}$ ), but only one as initial treatment, concomitantly receiving etoposide. ${ }^{15}$

At the end of the sixth week, 25 patients $(75.8 \%)$ showed a "better" response, three (9.1\%) showed an intermediate response and five (15.2\%) were unresponsive to the initial treatment. After the first treatment, 17 patients $(60.7 \%)$ had at least one relapse episode. In 16 cases, relapse occurred before 2 years of follow-up. All deaths occurred in patients with multisystem disease with organ dysfunction at diagnosis. The OS and DFS curves for all children are shown in Figure $1 \mathrm{~A}$.

The probability of OS for those who had a "better" response at the end of the sixth week was significantly higher than for those who did not have a response ( $p<$ 0.001 ; Figure $1 \mathrm{~B}$ ). The estimated probability of OS for patients with single-system disease was higher (100\%) than for those patients with multisystem disease $(74 \%$; 95\%CI 44.6-89.4\%; $p=0.047$ ).

The probability of DFS at 16 years amounted to $47.1 \%$ (95\%CI 23-68\%) for those patients with single-system disease and to $14.6 \%$ (95\%CI $2.5-36.8 \%$ ) for those with multisystem disease $(p=0.05)$. Age older $(n=14)$ or lower than 3 years $(n=19)$ did not have a significant impact on OS $(p=0.52)$ and DFS $(p=0.29)$.

Diabetes insipidus was the most common sequela, and was detected in seven patients (21\%), three of whom already had such sequela at diagnosis. Other sequelae included deafness in four patients and vertebra plana in one patient. After 16 years of follow-up, no cases of secondary neoplasms were reported.

Table 3 shows the degree of diagnostic accuracy, gender, stage, initial response to treatment, number of relapses, and the current situation of the 33 patients.

\section{Discussion}

In the present patient population, the distribution between sexes was similar; most studies describe ratios from 1.1 to 2 boys to every girl. ${ }^{7,14-17}$

In most cases, diagnosis was presumptive. The definitive diagnosis was established in only $21.2 \%$ of children, which points out to the difficulty in establishing it in

Table 2 - Clinical manifestations found at diagnosis in 33 children with langerhans cell histiocytosis

\begin{tabular}{lc}
\hline Manifestation & No. of patients ( $\mathbf{n} \mathbf{3 3})$ \\
\hline Bone lesions & $23(69.7 \%)$ \\
Enlarged lymph nodes & $16(48.5 \%)$ \\
Skin or mucocutaneous lesions & $11(33.3 \%)$ \\
Hepatomegaly & $9(27.2 \%)$ \\
Fever & $8(24.2 \%)$ \\
Splenomegaly & $7(21.2 \%)$ \\
Auditory canal involvement & $6(18.2 \%)$ \\
Gum or palate involvement & $3(9.1 \%)$ \\
Liver dysfunction & $3(9.1 \%)$ \\
Hematopoietic system involvement & $3(9.1 \%)$ \\
Lung involvement & $3(9.1 \%)$ \\
Diabetes insipidus & $3(9.1 \%)$ \\
Immunological disorders & $2(6 \%)$ \\
Vulvar lesion & $1(3 \%)$ \\
Lip lesion & $1(3 \%)$ \\
\hline
\end{tabular}


our setting. However, the CD1a monoclonal antibody is currently available in our institution for all cases.

Osteolytic lesions were the major initial manifestation of the disease, which is consistent with literature data. ${ }^{8-10,18,19}$ Plain X-ray is the examination of choice for the diagnosis and follow-up of most osteolytic lesions. In cases of persistent lesions, it may be necessary to use scintigraphy to determine their activity. Computed tomography is reserved for cases that cannot be defined by radiographic examination and for anatomically complex regions. ${ }^{20}$

Lymph node involvement was the second most frequent clinical manifestation at diagnosis, and was observed in
$48.5 \%$ of children in this study and in $23.5 \%$ of patients with single-system disease. Lymph node enlargement is described in less than $10 \%$ of children at the time of diagnosis. ${ }^{10}$ In the present study, patients whose disease concentrated only on lymph nodes had a presumptive or probable diagnosis. In these cases, the definitive diagnosis would be important to confirm the disease, since the frequency observed was much higher than that described in the literature. ${ }^{9}$

Skin lesions are often the first manifestation of $\mathrm{LCH}^{8}$ Of the 11 children of this study who had skin lesions, seven had had previous treatments for other pathologies, which might have caused a diagnostic delay, by regarding the onset of

Table 3 - Diagnosis and outcome of 33 children with Langerhans cell histiocytosis

\begin{tabular}{|c|c|}
\hline Diagnosis & \\
\hline Presumptive & 14 \\
\hline Probable & 12 \\
\hline Definitive & $7(\mathrm{CD} 1 \mathrm{a}=4 ; \mathrm{EM}=3)$ \\
\hline \multicolumn{2}{|l|}{ Stage } \\
\hline $1 \mathrm{~A}$ & 10 \\
\hline $1 \mathrm{~B}$ & 7 \\
\hline 2 & 16 \\
\hline \multicolumn{2}{|l|}{ Gender } \\
\hline Male & 17 \\
\hline Female & 16 \\
\hline \multicolumn{2}{|c|}{ Clinical response after 6 weeks of treatment* } \\
\hline "Better" response & 25 \\
\hline Intermediate response & 3 \\
\hline Disease progression & 5 \\
\hline \multicolumn{2}{|l|}{ Number of relapses in 28 childrent } \\
\hline 0 & 11 \\
\hline 1 & 8 \\
\hline 2 & 3 \\
\hline 3 & 2 \\
\hline 4 & 1 \\
\hline 5 & 2 \\
\hline 6 & 1 \\
\hline \multicolumn{2}{|l|}{ Current situation } \\
\hline Being followed up/in remission & 15 \\
\hline Discharged in remission & 7 \\
\hline Lost to follow-up during remission & 2 \\
\hline Lost to follow-up with active disease & 1 \\
\hline Receiving treatment & 4 \\
\hline Death & 4 \\
\hline
\end{tabular}



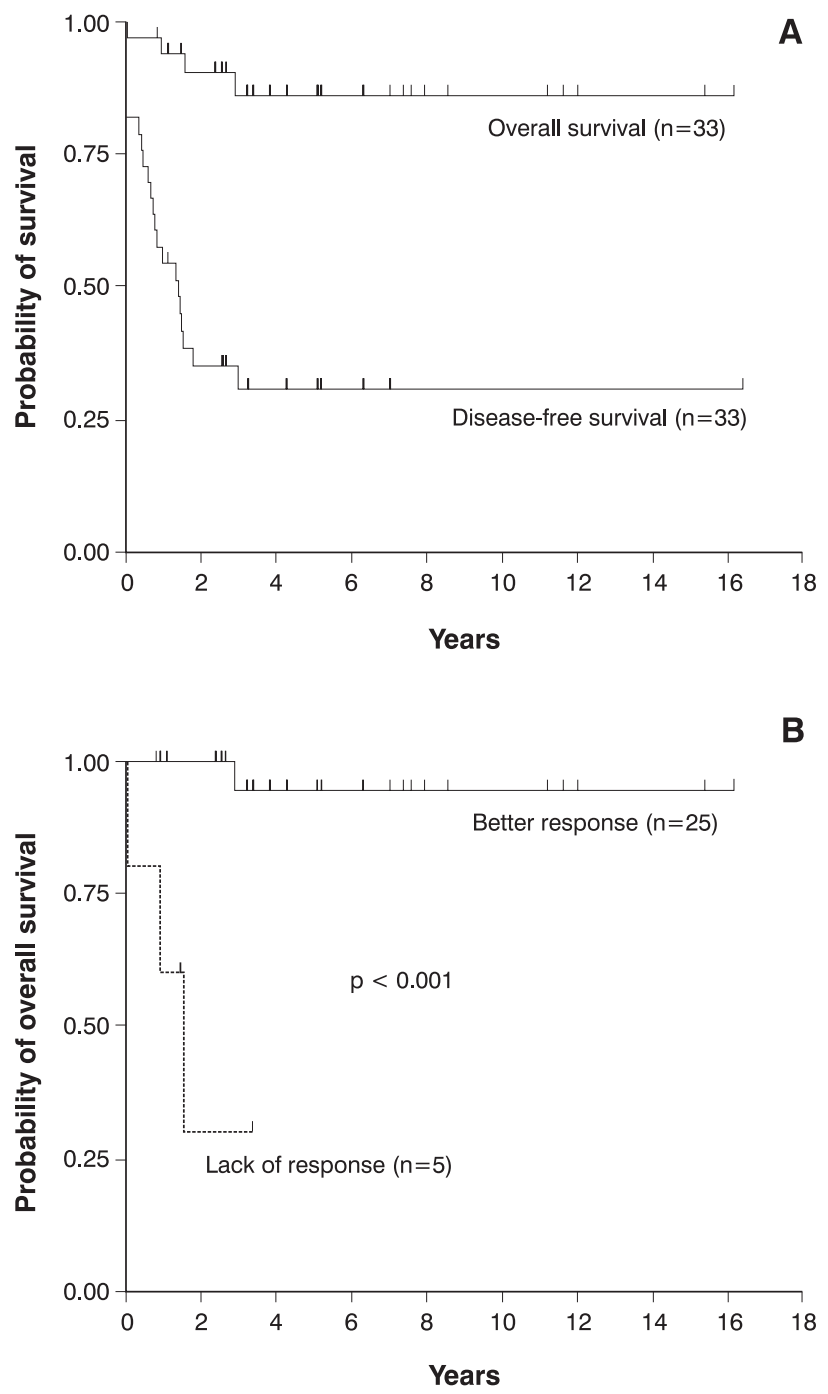

A) Overall survival (OS) and disease-free survival (DFS) curves for the 33 children. The estimated probability of OS at 16 years amounted to $86.1 \%(95 \% \mathrm{Cl} 66.6-94.6 \%)$; and the probability of DFS corresponded to $30.9 \%(95 \% \mathrm{Cl} 15.6-47.5 \%)$

probability of DFS corresponded to $30.9 \%$ (95\%Cl "15.6-47.5\%). B) The probability of OS for those who had a "better" response at the end of the sixth week of treatment ${ }^{14}(n=25)$ was $94.4 \%(95 \% \mathrm{Cl} 66.6-99.2 \%)$, compared to $30 \%(95 \% \mathrm{Cl} 1.2-71$. $9 \%)$ for those who did not have a response $(n=5 ; p<0.001)$. The three children with intermediate response survived, after one or more relapses.

The vertical markings on the curves in the OS graphs represent the surviving patients with the respective follow-up periods; the markings on the DFS curves represent surviving patients in first remission.

Figure 1 - Survival curves of children with Langerhans cell histiocytosis according to the Kaplan-Meier method

symptoms as the possible onset of the disease. The possible delay in the diagnosis of skin disease, due to its similarity to other diseases, has been reported. ${ }^{10}$

Ear involvement was described in six children at diagnosis and, in most cases, the possibility of LCH was not considered at first. This manifestation is more common among children with multisystem disease; the presence of persistent otitis, refractory to common treatments, should raise the suspicion of $\mathrm{LCH} .{ }^{10,21}$

LCH often affects the hypothalamic-pituitary axis, and diabetes insipidus is the most common manifestation. Quite often, it manifests with a median of 10 to 12 months after the onset of the disease, but it may precede it or appear several years later. ${ }^{10,22}$ The proportion of patients with diabetes insipidus varies considerably, with rates between 11 and $40 \%$. In the analyzed patient population, three patients had diabetes insipidus at diagnosis. The manifestation did not occur alone in none of the cases.

The percentage of cases of single-system disease was lower than that described in the literature, which is probably due to the small number of cases and, mainly, to the nondiagnosis or nonreferral of children with less severe forms of the disease. Most children with multisystem disease were aged less than 3 years at diagnosis, similarly to what has been described in most studies. ${ }^{7,16}$ Classically, age lower than 2-3 years indicates poor prognosis. In the present study, probably because of the small number of patients, such influence did not have any statistical significance. The association of this age group with multisystem disease explains why age is no longer regarded as an independent prognostic factor. ${ }^{12}$

Due to the observational study design and to the small number of patients, it was not possible to assess the relative efficacy of the different treatments used.

Among those patients with bone disease alone, seven $(87.5 \%)$ had at least one relapse episode. This rate is much higher than that described in the literature, which amounts to around $20 \%$. This is probably due to the fact that no maintenance treatment was used: recent studies have shown that the frequency of relapses is significantly different across different treatments and seems to decrease with longer treatment regimens. ${ }^{11,12,23}$

The progression of single-system disease to multisystem disease, which seldom occurs, has not been documented. ${ }^{5,11}$ Among the six patients with multisystem disease and skin lesions at diagnosis, four had been affected by skin lesions for at least 4 months, but it was not possible to determine whether or not these lesions were the only manifestation at diagnosis and then progressed to systemic disease. Progression of skin disease to multisystem disease or relapse of the disease at other sites have been both described by several authors. ${ }^{11,24,25}$

Patients with single-system LCH had an excellent OS prognosis (100\%). However, the probability of DFS at 16 years for this group of patients $(47.1 \%)$ shows some propensity for disease recurrence. ${ }^{14}$ The large number of relapses did not have an impact on OS, as described by some authors, showing that recurrence after total resolution is not a predictive factor for worse results regarding mortality. ${ }^{26}$ 
Response to initial treatment was a predictive prognostic factor for mortality. The group of patients that had a full or continuous response at the end of the first 6 weeks of treatment had an OS probability of $94.4 \%$, compared to $30 \%$ in the group of unresponsive patients. This finding is similar to the first international cooperative studies, which revealed that response to initial treatment assessed at the end of the sixth week - is an important prognostic factor for multisystem LCH and should be used for early changes in treatment. ${ }^{14,27,28}$

As described in the literature, the group of patients with multisystem disease and organ dysfunction at diagnosis had a very poor prognosis. ${ }^{5,14}$ The results of major cooperative studies - DAL HX 83/90, LCH I and LCH II clearly demonstrated the unfavorable prognostic influence of organ dysfunction and lack of initial response to treatment. ${ }^{29}$ These data highlight the need to strictly assess response to treatment in the sixth week and the need to find new therapeutic alternatives for those patients with involvement of risky organs and who are unresponsive to treatment in this period.

The probability of DFS for those with multisystem disease $(14.6 \%)$ was smaller, and the relapse rate $(75 \%)$ was larger than that described in the literature. However, most literature data refer to patients submitted to at least 6 months of treatment, which probably explains the differences observed. The retrospective comparison of the DAL HX, LCH I and LCH II studies suggests that longer treatments may reduce the relapse rate. ${ }^{12}$

The number of sequelae found in the present study was smaller than that observed by Haupt et al., who assessed 182 patients with single-system and multisystem disease and detected sequelae in $52 \%$ of them. This difference can be explained by the small number of patients and by the fact that the sequelae were not systematically investigated in the present study. The length of follow-up does not seem to have hindered the analysis of sequelae in a significant way, since most of the sequelae appear within the first years after diagnosis. Diabetes insipidus was the most frequent sequela, which is consistent with most reports. ${ }^{28,30}$

No cases of secondary neoplasms were observed after a 16-year follow-up. The development of secondary neoplasms after the use of etoposide has been described in a small number of cases. ${ }^{12}$

Despite the wide variety of clinical manifestations, also observed in the present study, the diagnosis of $\mathrm{LCH}$ is not difficult when its possibility is contemplated. ${ }^{9,10}$ Ten children with symptoms for at least 4 months were identified. It has been well established that longer activity of the disease is associated with an increase in morbidity. ${ }^{28}$ In most cases, the disease was benign, with low mortality rates. However, it showed high probability of relapses and sequelae, causing remarkable morbidity, as described in the literature.

These data show the importance of making the disease more widely known, especially among pediatricians, in order to allow for an early diagnosis and fewer chances of sequelae. Cooperative and prospective studies should be carried out to provide greater knowledge about the disease in our setting, and to improve the clinical management of children suffering from this disease.

\section{References}

1. Chu T, D'Angio GJ, Favara BE, Ladisch S, Nesbit M, Pritchard J. Histiocytosis syndromes in children. Lancet. 1987;2:41-2.

2. Favara BE, Feller AC, Pauli M, Jaffe ES, Weiss LM, Arico M, et al. Contemporary classification of histiocytic disorders. The WHO Committee on Histiocytic/Reticulum Cell Proliferations. Reclassification Working Group of the Histiocyte Society. Med Pediatr Oncol. 1997;29:157-66.

3. Egeler RM, Annels NE, Hogendoorn PC. Langerhans cell histiocytosis: a pathologic combination of oncogenesis and immune dysregulation. Pediatr Blood Cancer. 2004;42:401-3.

4. Nezelof C, Basset F. An hypothesis Langerhans cell histiocytosis: the failure of the immune system to switch from an innate to an adaptive mode. Pediatr Blood Cancer. 2004;42:398-400.

5. Arceci RJ, Longley BJ, Emanuel PD. Atypical cellular disorders. Hematology Am Soc Hemat Educ Program. 2002;:297-314.

6. Arico M. Langerhans cell histiocytosis in adults: more questions than answers? Eur ] Cancer. 2004;40:1467-73.

7. Nicholson HS, Egeler RM, Nesbit ME. The epidemiology of Langerhans cell histiocytosis. Hematol Oncol Clin North Am. 1998;12:379-84.

8. Egeler RM, D'Angio GJ. Langerhans cell histiocytosis. J Pediatr. 1995; 127:1-11.

9. Broadbent V, Egeler RM, Nesbit ME Jr. Langerhans cell histiocytosis - clinical and epidemiological aspects. $\mathrm{Br}$ J Cancer Suppl. 1994;23:S11-6.

10. Arico M, Egeler RM. Clinical aspects of Langerhans cell histiocytosis. Hematol Oncol Clin North Am. 1998;12:247-58.

11. Titgemeyer C, Grois N, Minkov M, Flucher-Wolfram B, Gatterer-Menz I, Gadner H. Pattern and course of single-system disease in Langerhans cell histiocytosis data from the DAL-HX 83- and 90-study. Med Pediatr Oncol. 2001;37:108-14.

12. Histiocyte Society. Treatment protocol of the Third International Study for Langerhans Cell Histiocytosis. 2nd ed. Viena: Histiocyte Society; 2002.

13. Simms S, Warner NJ. A framework for understanding and responding to the psychosocial needs of children with Langerhans cell histiocytosis and their families. Hematol Oncol Clin North Am. 1998;12:359-67.

14. Gadner H, Grois N, Arico M, Broadbent V, Ceci A, Jakobson A, et al. A randomized trial of treatment for multisystem Langerhans' cell histiocytosis. J Pediatr. 2001;138:728-34. 
15. Viana MB, Oliveira BM, Silva CM, Rios Leite VH. Etoposide in the treatment of six children with Langerhans cell histiocytosis (histiocytosis X). Med Pediatr Oncol. 1991;19:289-94.

16. Hamre M, Hedberg J, Buckley J, Bhatia S, Finlay J, Meadows A, et al. Langerhans cell histiocytosis: an exploratory epidemiologic study of 177 cases. Med Pediatr Oncol. 1997;28:92-7.

17. A multicentre retrospective survey of Langerhans' cell histiocytosis: 348 cases observed between 1983 and 1993. The French Langerhans' Cell Histiocytosis study group. Arch Dis Child. 1996;75:17-24

18. Azouz EM, Saigal G, Rodriguez MM, Podda A. Langerhans' cell histiocytosis: pathology, imaging and treatment of skeletal involvement. Pediatr Radiol. 2005;35:103-15.

19. Kilpatrick SE, Wenger DE, Gilchrist GS, Shives TC, Wollan PC, Unni KK. Langerhans' cell histiocytosis (Histiocytosis X) of bone. A clinicopathologic analysis of 263 pediatric and adult cases. Cancer. 1995; 76:2471-84.

20. Meyer JS, De Camargo B. The role of radiology in the diagnosis and follow-up of Langerhans cell histiocytosis. Hematol Oncol Clin North Am. 1998; 12:307-26.

21. Surico G, Muggeo P, Muggeo V, Conti V, Novielli C, Romano A, et al. Ear involvement in childhood Langerhans' cell histiocytosis. Head Neck. 2000;22:42-7.

22. Grois NG, Favara BE, Mostbeck GH, Prayer D. Central nervous system disease in Langerhans cell histiocytosis. Hematol Oncol Clin North Am. 1998;12:287-305.

23. Jubran RF, Marachelian A, Dorey F, Malogolowkin M. Predictors of outcome in children with Langerhans cell histiocytosis. Pediatr Blood Cancer. 2005;45:37-42.

24. Munn S, Chu AC. Langerhans cell histiocytosis of the skin. Hematol Oncol Clin North Am. 1998;12:269-86.
25. Longaker MA, Frieden IJ, LeBoit, PE, Sherertz EF. Congenital "self-healing" Langerhans cell histiocytosis: the need for long-term follow-up. J Am Acad Dermatol. 1994;31:910-6.

26. Gadner H, Heitger A, Grois N, Gatterer-Menz I, Ladisch S. Treatment strategy for disseminated Langerhans cell histiocytosis. DAL HX-83 Study Group. Med Pediatr Oncol. 1994;23:72-80.

27. Minkov M, Grois N, Arico, M, Braier J, Broadbent V, Donadieu J, et al. Preliminary results of the LCH - II trial of the Histiocyte Society. Med Pediatr Oncol. 2003;41:263.

28. Minkov M, Grois N, Heitger A, Pötschger U, Westermeier T, Gadner $H$. Treatment of multisystem Langerhans cell histiocytosis. Results of the DAL-HX 83 and DAL-HX 90 studies. Klin Padiatr. 2000;212:139-44.

29. Minkov M, Grois N, Heitger A, Pötschger U, Westermeier T, Gadner $\mathrm{H}$, et al. Response to initial treatment of multisystem Langerhans cell histiocytosis: an important prognostic indicator. Med Pediatr Oncol. 2002;39:581-5.

30. Haupt R, Nanduri V, Calevo MG, Bernstrand C, Braier JL, Broadbent $V$, et al. Permanent consequences in Langerhans cell histiocytosis patients: a pilot study from the Histiocyte Society Late effects study group. Pediatr Blood Cancer. 2004;42:438-44.

Correspondence:

Benigna Maria de Oliveira

Faculdade de Medicina da UFMG, Departamento de Pediatria

Av. Alfredo Balena, 190

CEP 30130-100 - Belo Horizonte, MG - Brazil

Tel.: +55 (31) 3248.9442

Fax: +55 (31) 3248.9772

E-mail: benigna@uol.com.br 